\title{
Delian MODES: \\ Listening for Delia Derbyshire in Histories of Electronic Dance Music \\ Feature Article $\longrightarrow$
}

FRANCES MORGaN

Royal College of Art (UK)

\begin{abstract}
This paper examines the work of English composer and sound designer Delia Derbyshire (1937-2001) in the context of histories of EDM and historical accounts of women in electronic music. Examining the media discourse around Derbyshire, whose reputation has grown significantly since her death, I consider how Derbyshire has come to be regarded posthumously as both a pioneering electronic composer and a forerunner of dance music and electronica in the UK. I consider how these identities are related to her gender, and how gender is constructed and expressed in the discourse around her life and work, with reference to the musical-critical phenomenon of hauntology.
\end{abstract}

KeYwords: Delia Derbyshire, BBC Radiophonic Workshop, electronica, feminist histories, archival practice, music blogging, music journalism, hauntology, fan studies

Frances Morgan is a music and media critic based in London. A contributing editor to The Wire magazine, she is currently a PhD candidate in the Critical Writing in Art \& Design department at the Royal College of Art, researching the history of EMS in collaboration with the Science Museum. She has recently published articles in Organised Sound, Fylkingen Tongues, The Wire and Sight \& Sound.

Dancecult: Journal of Electronic Dance Music Culture 9(1): 9-27

ISSN 1947-5403 @2017 Dancecult http://dj.dancecult.net

http://dx.doi.org/10.12801/1947-5403.2017.09.01.01

\section{dsencecult}




\section{Delia Derbyshire's Life and Legacy}

Delia Derbyshire (1937-2001) occupies a unique place in histories of electronic music. The music and sound design that she created while working at the BBC Radiophonic Workshop, London, between 1963 and 1973 was heard by countless viewers and listeners of TV and radio; yet-like many of her colleagues-she was not regarded primarily as a composer, but as a creator of what the BBC termed "special sound", that is to say radiophonic sound effects, as well as electronic realisations of music composed by others. ${ }^{1}$

Born in Coventry, in the East Midlands, and educated in music and mathematics at Cambridge University, in 1963 Derbyshire was employed by the Radiophonic Workshop, an adjunct of the BBC's drama department set up in 1958 to provide sound effects for radio dramas. The Workshop expanded to provide electronic themes for numerous TV and radio dramas, documentaries and news programmes throughout the 1960s, 70s and 80s. Derbyshire's best-known work was an electronic realisation of the composer Ron Grainer's theme tune to $\mathrm{Dr} W h o$, the hugely popular science fiction series. The $\mathrm{Dr} W h o$ theme, which was the first electronic TV theme tune to be broadcast on British TV, is instantly recognisable to generations of viewers in the UK and worldwide.

Many of Derbyshire's compositions abandon the conventions of the soundtrack music of their time, and are closer in form and intention to classical electronic or electroacoustic works. Pieces such as "The Delian Mode" and "Blue Veils and Yellow Sands" (Derbyshire, BBC Radiophonic Music, 1968), for example, are structured around slow transformations and shifting layers of sound with the aim of exploring subtleties of pitch and timbre. Desmond Briscoe, the former head of the Workshop, recalled that, "Mathematics of sound came naturally to [Derbyshire] and she could take a set of figures and build them into music in a way quite different from anyone else", creating "very beautiful-almost unearthly-and quite remarkable music" (Briscoe 1983). However, soon after leaving the BBC in 1973, Derbyshire retreated from music, composing only in private, if at all.

Shortly before her death, Derbyshire's work from the 1960s and '70s started to be reappraised by electronic and rock musicians, as well as those interested in histories of British broadcasting, and she became recognised as an innovator of electronic music.

Since 2001, interest in Derbyshire's life and work has grown rapidly. On the one hand, Derbyshire's posthumous recognition is part of a more general reappraisal of the pioneering work done by the BBC Radiophonic Workshop during the years Derbyshire worked there, as scholars of electronic music and media, as well as the BBC itself, have come to recognise the value of the Workshop's output. However, it is Derbyshire in particular who has entered the wider cultural imagination, prompting scholarly attention (Niebur 2010; Winter 2015), Kara Blake's documentary film The Delian Mode (2009), a stage play (Standing Wave, Nicola McCarthy 2004), a radio docu-drama (Blue Veils and Golden Sands, Martyn Ware 2002), museum exhibits, and the vinyl release of rare recordings such as the soundtrack to Anthony Roland's film Circle of Light (composed by Derbyshire with artist Elsa Stansfield in 1972 and released by Trunk Records in 2016). Derbyshire has been visually represented 
on T-shirts and posters. She is frequently cited in list-based articles about pioneers of electronic music, particularly those that focus on female musicians. Her position as one of a small number of female practitioners to have worked in the Radiophonic Workshop has caused her to be celebrated as a role model for women working in all forms of electronic music and music technology. In the circulation of images of her at work in the Workshop, she can be said to have become iconic.

In 2017, which would have been the year of her eightieth birthday, a series of events organised under the heading Delia Derbyshire Day took place around the UK. ${ }^{2}$ Initially a grassroots initiative set up in Manchester in 2012 by electronica artist Caro C, Delia Derbyshire Day is now a publicly funded touring event, working in collaboration with Derbyshire's archive at the University of Manchester, as well as other partners including the PRS (Performing Rights Society) Fund for New Music, Full of Noises festival and Digital Women's Archive North. These events included educational workshops for schoolchildren, premieres of new audiovisual works by emerging artists, and lectures from Derbyshire's former Radiophonic Workshop colleagues. Delia Derbyshire Day provides a useful illustration of Derbyshire's current status in UK public arts culture and the way in which her legacy has been instrumentalised to promote new and emerging artists whose work responds to hers.

Less explored, and less formally recognised, has been the relationship between the growth of Delia Derbyshire's legacy and certain movements in British electronic dance music culture; and the position of Derbyshire within media discourse around EDM. This paper examines how the music of Derbyshire-and the persona with which her music is inextricably entwined - has been adopted into several EDM histories. One is the history of women's involvement in EDM; another is a more locally situated narrative about electronic dance music and electronica in the UK. In this paper I ask why the authors of these narratives have been eager to claim Derbyshire as a pioneer in a form with which she had no personal involvement, and consider the basis of these claims by drawing on selected works by the composer. I consider Derbyshire's legacy from the perspective of feminist historical and archival practice as well as with reference to the musical-critical phenomenon of hauntology (Reynolds 2006, 2011; Fisher 2014; Pattie 2016).

\section{Electronic Music Histories, Underground Media and Fandoms}

Through my citation of articles and other texts published by the BBC, Mixmag, DJ, The Wire and various blogs in this paper, I acknowledge the importance of all kinds of media in shaping perceptions of electronic music's history and its current practice (while acknowledging that "the media" is being used here as shorthand for very different forms of discourse ranging from marketing copy on a music retail site to an independent print magazine). The media play a key role in presenting, framing and delineating areas of music in which such traditional genre boundaries demarcating "popular" and "classical", or, say, "EDM" and "ambient', or "techno" and "noise" are blurred or problematised; they also, 
increasingly, present accounts of electronic music history, which might otherwise remain an area of specialist study, to a general public that includes groups such as record collectors, music technology enthusiasts and EDM fans.

In "Pioneer Spirits: New Media Representations of Women In Electronic Music History" (Morgan 2017: 238-49), I argue that, "print and online media play a role in making visible certain aspects of electronic music history to consumers who might also be practising musicians, music scholars, and potential researchers", while "[a]cademic writers and researchers exploring the relations between gender, sound and technology increasingly use the same platforms as online critics to discuss, promote and present their interests" (Morgan 2017: 239). In other words, many of us occupy multiple identities, as readers, consumers, scholars, fans, and practitioners, and our use of media is equally diverse, overlapping and multi-directional. This is especially the case in areas whose scholarship still occupies a marginal position in the academy, such as scholarship of EDM, and the scholarship of feminist and other activist practices.

While stories concerning electronic music histories and celebrating post-war electronic music pioneers have become prevalent in popular music media of all kinds in the last decade, Delia Derbyshire was one of the first figures to be recognised in this way, as underground, non-commercial and user-generated media began to amplify her life and work in the late 1990s and early 2000s. A key driver of Delia Derbyshire's posthumous recognition has been the activities of musician-enthusiasts such as Pete Kember (aka Sonic Boom from the band Spacemen 3), Drew Mulholland, and John Cavanagh, who carried out interviews with Derbyshire in the years shortly before her death (Kember 2000; Cavanagh 1998), ${ }^{3}$ and Martin Guy, who set up the website delia-derbyshire.net and subsequently Wikidelia; as well as the members of the Delia Derbyshire mailing list, which has been running since $2003 .{ }^{4}$

The work of Guy and other independent historians to catalogue and make public Derbyshire's music through underground media channels has been complicated by formalisation of the Delia Derbyshire Archive, the contents of which were acquired by Manchester University's Centre For Screen Studies from Derbyshire's former colleague Mark Ayres, in 2009, and are now held at the John Ryland Library. ${ }^{5}$ Although Guy has visited the archive, he is critical of what he considers to be its lack of accessibility to the public, writing, with regard to Derbyshire's unpublished tapes, "Someone should just put it all on the peer-to-peer file sharing network but so far no one [who is] able to [do this] has taken the initiative" (Guy 2017). It is clear that Guy's continuous amassing and cataloguing of material relating to Delia Derbyshire is in part a means of expressing his affection for her, which he reveals in more personal reflections, writing that, Derbyshire "has visited me in dreams many times, always a positive, encouraging, sometimes delighted figure" (Guy 2017).

Although a detailed study of this area is beyond the reach of this essay, it would be informative to look at fan-led media projects such as Wikidelia and the Electronic Church of St Delia in the context of cult fandom as described by Matt Hills (2002), in order to analyse in more detail how notions of gender are constructed and expressed in different 
kinds of electronic music histories. Wikidelia meets the criteria of cult fandom in the sense that its relationship to Derbsyhire is highly affective and emotional; the project is enduring rather than transient; and it is based around a subject who is no longer living (Hills 2002: x) To think of Wikidelia, and other such user-led projects, as products of fandom is not to trivialise them or detract from their validity as acts of research, but to understand them as being produced as part of the formation of a fan identity, which is an identity that "performs cultural work" (Hills 2002). While the construction and expression of gender within fandom is a complex topic, it seems clear that the fan's experience of certain texts or figures within cult fandom is related to "the social experience of gender as well as to the iteration of gender codes" (Hills 2002: 127).

An investigation of Derbyshire fandom would also allow for reflection upon the differences and similarities between male, female and gender non-conforming fans' perceptions of Derbyshire, considering how their fandom is performed and through which kinds of creative activities. For example, initiatives such as Delia Derbyshire Day could be examined for their roots in fandom by women musicians, as could the production of the feminist histories of electronic music as described in section 5. It is of course possible, as Catherine Grant argues in her study of the influence of second-wave feminism on contemporary art, to be a "fan of feminism" (Grant 2011); and it is by writing through my own tentative identity as a "scholar-fan", pace Hills, of both electronic music and feminist criticism, that I develop many of the arguments in this paper. ${ }^{6}$

To return to the example given above, I suggest that Guy's characterisation of Derbyshire as a benevolent apparition that visits him in his dreams to thank him for his archival efforts is a highly gendered expression of his fandom; and that similarly gendered expressions can be found, albeit less overtly, in more professional, objective accounts of Derbyshire in "official" media accounts. Although this more mainstream discourse around Derbyshire does not always objectify her as explicitly as a fan discourse might, it frequently combines an uncritical admiration with a desire to own and assess previously unheard material that she may or may not have intended for public consumption.

As histories of post-war electronic music become a more familiar part of the media discourse around certain forms of electronica and EDM, there has also been an increase in releases of archival electronic music by labels also associated with new electronica, experimental music and EDM, such as Public Information, ${ }^{7}$ as well as the formation of new imprints, series and sub-labels specifically for such releases. ${ }^{8}$ In some cases, the language and marketing structures associated with micro-genres of dance music have been assimilated by labels that release archival recordings of electronic composition. I propose that this is not merely a pragmatic commercial decision-in that a retailer like Boomkat sells electronic music of all kinds and delivers these musics in a similar way regardless of genre-but that it acknowledges a shared territory between what we might call post-war electronic music (that is to say, modernist electronic music realised primarily in academic and broadcasting studios during the post-Second World War period) and certain areas of EDM culture. 
In the following section I discuss some examples of how Delia Derbyshire's work has been positioned within this territory as both representative of its time and uncannily predictive of various dance music futures. I ask what identities and desires are articulated in these claims and how Derbyshire's gender both encourages and problematises this discourse.

\section{Possible Futures: Delia Derbyshire as Rave Prophetess}

In this section, I discuss a number of media stories that position Delia Derbyshire's music as predictive of electronica and EDM. In part (i) I look at the discovery of previously unheard tapes that were greeted by some media outlets as "evidence" of Derbyshire's pioneering use of technology which leads her to produce music that sounds like EDM. In part (ii), I examine how a similar claim has been made for Derbyshire's prescience in making music that sounds "proto-rave"; however, this claim is made from a musical-cultural perspective rather than a technological one. In both accounts, I argue, we can see how Derbyshire has been framed within narratives of music technology and music journalism as a figure through whom authors can express certain ideas about musical and technological futures.

\section{(I) "Now AS MUCH AS THEN"}

In 2008, the BBC website ran a story about the discovery of an archive of Delia Derbyshire's tapes (these recordings went on to become the basis of the Derbyshire archive). The story accompanied an instalment of $P M$, a general magazine programme on BBC Radio 4.

The article paid particular attention to a piece of music that "sounds like a contemporary dance track, which was recorded, it is believed, in the late sixties" (Wrench 2008). Musician Paul Hartnoll, from the group Orbital, was quoted as saying that the music "...could be coming out next week on [left-field dance label] Warp Records... It's incredible when you think when it comes from. Timeless, really. It could be now as much as then" (Wrench 2008). This aspect of the story was picked up by music technology websites including Music Radar, which ran a story under the headline, "New Evidence that Doctor Who Composer Invented Dance Music" (Rogerson 2008) and Create Digital Media (CDM) (Create Digital Media 2008a).

The music in question is a piece named "Dance from Noah" (Derbyshire, Sounds from... $E M S, 1972$ ), written for the BBC Schools programme and first broadcast in May 1971. It was also included on a promotional flexi disc produced by the synthesiser company EMS (Electronic Music Studios), whose synthesisers Derbyshire used to realise the piece. "Dance from Noah" is a short cue consisting of a percussion track overlaid with a simple bass figure. The time signature appears to be one of Derbyshire's favoured compound ones, in this case $12 / 8$, although it is hard to define precisely. There is a lead melody consisting of two or three almost identical phrases, and a counterpoint that signals the cycling of the melody back to the first phrase halfway through the cue and modulates between $\mathrm{F}$ major and F minor.

While there are elements in the track's melodic content that are reminiscent of synthesizer lines from electro or techno music, the use of counterpoint and the staccato 
and harpsichord-like tone of the second melody line owe as much to Derbyshire's fondness for Baroque keyboard music. The rhythmic aspects of "Dance from Noah" are more noteworthy. In repurposing sounds such as white noise and a low frequency oscillator to create its beats, rather than a drum machine or sampled percussion, it could be aligned with experimental forms of techno in which texture is used for rhythmic purposes, such as the music of Pan Sonic. The focus on rhythmic layering and the relation of rhythm to meter provides the clearest link to the way EDM is structured; while the fragmentary nature of the track leaves its development open to question in a way that makes it consistent with the longer, gradually unfolding structures of a dance track.

The excitement that greeted the track was due to that fact that, because of the way it was presented on the radio show, it was thought to date from the time in which Derbyshire had access only to sound generators and tape-splicing techniques-which would make "Dance from Noah" truly remarkable. Hartnoll commented:

I've got a shedload of synthesizers and equipment, whereas Delia Derbyshire got out of the Radiophonic Workshop when synthesizers came along. I think she got a bit disheartened and a bit bored with it all when the synthesizer came along and it all became a little too easy (Wrench 2008).

However, while it is true that Derbyshire left the BBC Radiophonic Workshop soon after the Workshop began using synthesizers widely, and was known not to enjoy using them as much as tape techniques (Niebur 2010: chapter 4), she was also an early adopter of the EMS VCS3, an instrument whose sound would not be unfamiliar to Paul Hartnoll as it is well-known as the first British-made commercial synthesizer. The misapprehension was corrected by archivist David Butler on the CDM message board, after some commenters wondered if the track was a fake, as they had surmised that it must have been created using a synthesizer (CDM 2008b).

In the presentation of this story, we can see how Derbyshire's technical mastery is foregrounded so much so that it is portrayed inaccurately and becomes the subject of a message board debate. The desire to present Derbyshire as someone who was so preternaturally skilled that she could actually work outside of the realms of musical-technological possibility is apparent in Hartnoll's comments, as is a need to frame the music within a familiar context of underground EDM: that of the UK label Warp records. Derbyshire is thus presented as an outlier who can nonetheless be situated within a continuum of British underground electronic music that, in the case of Warp-released artists such as Aphex Twin and Boards of Canada, has taken influence from the music created by the BBC Radiophonic Workshop. Here we see how the listener, with the help of information they have been given, co-creates the (history of the) music, adding to it their own desires, references, practices and memories. ${ }^{9}$

In foregrounding Derbyshire's technical mastery, Hartnoll and the writers and commenters of CDM perpetuate a techno-deterministic narrative that not only situates Derbyshire as primarily a technological innovator, rather than a composer whose interest 
in the mathematics of sound far outweighed her interest in hardware, but also suggests that technological innovation is the most important factor in discussing electronic music's history and development. This is not an uncommon attitude within electronic music; yet I would argue that it is a problematic one that prioritises masculinised ideas of technological achievement in which "to be in command of the very latest technology signifies being involved in directing the future" (Wacjman 1991: 144). Here, knowledge of the history of music technology, as well as possession of its tools (the "shedload of synthesizers"), is used by Hartnoll to demonstrate his own position of power and authority in relation to Derbyshire's history. The commenters on CDM also participate in a techno-deterministic dialogue in which they doubt Derbyshire's authorship of the track based on their knowledge of music technology-authorship which is in question until another male authority figure, the archivist, confirms it to be true.

\section{(II) Proto-everything}

The previous example showed how Delia Derbyshire's work is situated in a narrative of musical-technological innovation and advancement, as well as a narrative of discovery of "lost" recordings familiar to record collectors. In the following paragraphs, I will consider how Derbyshire has been portrayed in popular music criticism, within a discourse of popular modernism as defined by Mark Fisher and others.

This discourse can be traced to the journalism of UK-based music papers such as $N M E$ in the 1980s, and resurfaced in a culture of blogging in the early to mid-2000s, with some crossover into print journalism via The Wire magazine. Influenced by theorists such as Frederic Jameson, this discourse is committed to an idea of the future-or futures plural-that is articulated in certain forms of pop culture, particularly music and television, described by Mark Fisher as exemplifying "popular modernism"; that is to say, cultural products through which "the elitist product of modernism was retrospectively vindicated" and modernist techniques were "not only disseminated, but collectively reworked and extended" (Fisher 2014: 22). The music made by the BBC Radiophonic Workshop has been frequently cited by Fisher and others as an example of popular modernism, due to its use of avant-garde techniques and innovative technologies to create music that would be heard in popular and domestic settings. The development of the musical-critical phenomenon dubbed "hauntology" by Fisher and others, notably Simon Reynolds, is also based in this critical milieu.

Certain forms of British electronic dance music such as rave, hardcore, jungle/ drum'n'bass and various forms of electronica feature heavily in this discourse, embodying once again an idea of futuristic technologies and techniques that were not only available to but enthusiastically embraced and then further developed by communities of musicians who operated independently from mainstream channels but created popular, if not populist music. The idea that British dance music culture is historically significant in itself and is 
situated within, and refers to, an historical continuum of modernist electronic music can be seen in an increasing awareness among musicians and critics of dance music's sonic and social histories, as well as having influenced the discussion around histories of electronic music more generally.

This notion of a continuum of futuristic popular British electronic music is apparent in blogger Robin Carmody's obituary for Delia Derbyshire written for The Wire magazine in 2001. He refers to her Dr Who theme as a "throbbing piece of proto-electronica" and a composition titled "Pot Au Feu" (Derbyshire, BBC Radiophonic Music, 1968) as a "protorave track decades before its time" (Carmody 2001: 14).

There are a number of reasons why Carmody might single out this track. Firstly, it is an anomaly among the Derbyshire recordings that were available at the time, as it was not a theme tune for a particular programme, but a kind of collage, made to showcase the possibilities of the Workshop as well as Derbyshire's skills. ${ }^{10}$ Secondly, it contains sonic markers shared with some forms of EDM from the 1990s, in this case acid house and hardcore techno.

Lasting for just under four minutes, "Pot Au Feu "starts with a bubbling, noisy sound which cuts off to forefront a tonally ambivalent bass line that brings to mind the sound of a 303 or other sequencer, with high, metallic tones playing a simple melody centred around minor seconds and sevenths. It then changes key and a faster rhythm, made from treated hand percussion, replaces the bass line with a variation of the previous melody coming in. The melody sounds as if it was originally played on a stringed instrument such as a zither, and there are sporadic chords from an electric guitar later in the track, but the overall texture is electronic, with sine tones creating a harmony line towards the end of the piece. The insistent introduction of the second melody - twelve notes at the same pitch hammered out insistently, followed by a four note upward pattern-catches the attention and is certainly the hook of the piece, but at the same time there is a sense of various different elements vying for attention, with no one element settling into the role of the "lead" instrument.

The disorientation created by unfamiliar sounds, or familiar sounds in unusual configurations; the approximate pitching of the first bassline; the treated guitar that sounds deliberately synthetic - these are all traits with analogues in early UK EDM. Elsewhere, Carmody refers to "an alarm-bell of a hook recalling the 'panic/excitement' lines so prevalent in early 90s hardcore", ${ }^{11}$ referring to the aggressively urgent, angular melodies found in hardcore techno. There is also a sense of tension and release evoked by the stopping of one element and the sudden replacing or reappearance by another that corresponds with the "dynamic of removal and return" that pervades almost all EDM (Butler 2006: 91). The comparison to hardcore could also allude to the tempo of the track, which is fast and suggests techno rather than house music. It would also not be surprising to read an article written in the same time period that compared this piece of music to mid-90s drum ' $n$ ' bass, as the shifting, galloping rhythm and the drifting, glassy melody recalls the sound field created by producers such as Dillinja. 
Like Hartnoll's response to "Dance from Noah" in part (i), Carmody's assessment of "Pot Au Feu" can be said to be co-creative, assembling an interpretation of the music that corresponds with a particular musical/historical model. While the former focuses on technology and sonic practice, the latter is more concerned with a musicological and cultural reading, yet both arrive at the conclusion that Derbyshire's music can be heard as predictive of EDM. In part (iii), concluding the section, I examine the differences between these interpretations and the role that Derbyshire's gender might play in the formation of both.

\section{(III) METHODS AND MEDIATION}

As we can see from these two examples, there are structural, processual and sonic parallels that can be drawn between Delia Derbyshire's compositions and those created in the 1990s by EDM producers, in the use of electronic sounds as melody sources, simple, often minorkey or modulating melodies, unusual rhythms created with treated percussion sounds, and indeterminately pitched elements that treat pitch as more akin to timbre, a practice common to sample-based dance music (Butler 2006: 66).

While the working methods used by Derbyshire in 1968 and 1971 and by dance musicians in the 1980s and 1990s are in many ways different, instances of path dependency, most obviously between the cutting and repurposing of recorded sounds on tape and the practice of digital sampling, highlight a similarity between compositional methodologies despite technological and cultural differences. Likewise, the sonic treatments available to Derbyshire, such as reverb, delay, and high and low pass filters, and the preference for clearly "electronic" sounds such as oscillators and noise generators, are also present in EDM, even though the technologies for obtaining those sounds have changed. Here, the common ground between post-war modernist electronic music and EDM production that I refer to in section 2 of this paper can be characterised primarily as one of shared practice.

However, the aim of Carmody and other writers of his milieu is not to examine corresponding methods of music making across historical periods so much as to put Derbyshire's music into a critical dialogue with what they consider to be the most forwardlooking of contemporary electronic music, which is not the "classical" electronic music that Derbyshire herself strove towards, but the popular music for which she had less regard. Reviewing the 2002 re-release of BBC Radiophonic Music, also in The Wire, Ken Hollings hears echoes of a whole lineage of electronic popular music, not just EDM, in Derbyshire's "Ziwzih Ziwzih OO-OO-OO" (BBC Radiophonic Music, 1968), a composition written for TV adaptation of an Isaac Asimov story: "Its backwards intonations and inflexible phrasing have the whole history of techno-pop's alien otherness, from [David] Bowie and Tubeway Army right through to Fischerspooner, written into them" (Hollings 2002: 66). Here, Derbyshire's work is set in a narrative of electronically mediated pop music in which new technological possibilities produce new modes of expression. 
In this section, we have seen how certain desires are articulated in the ways in which an historical piece of music is heard and described by its later listeners and how these desires can also be presented within/as evidence-based, factual news items. The figure of Delia Derbyshire, who is of course no longer alive to articulate her own desires, becomes a mediator between different technological and cultural realms, supporting writers such as Carmody and Hollings's suggestion that EDM is part of a continuum with the experimental electronic music created by Derbyshire, and that one of EDM's points of origin is the electronic sound and music transmitted by British public service broadcasting. The writers' own experience of this music, via exposure to TV and radio as children and young adults, therefore becomes significant; and they, too, become participants in the narrative. Rather than centring Derbyshire, this narrative predominantly centres the listening, writing subject and their-generally his-body of knowledge and range of memories. Referring to Mark Butler's (2006) notion of the "masculine kind of stories" that proliferate in EDM histories (and which will be discussed further in section 5), it could be said that these also constitute masculine stories, because they are centred in men's experiences and knowledge of electronic music, and the ways in which they demonstrate that knowledge.

While these critical appraisals celebrate Derbyshire's prescience, they have the effect of pushing many aspects of her work to the background: her pursuit of "serious" music, which included a period assisting Luciano Berio (Butler 2014: 71); her affinity for sculpture and other forms of visual art (Winter 2015: 138-40); and the study of mathematics and analysis of acoustic phenomena that resulted in her more abstract works, are disregarded in favour of technical prowess and an accidental correspondence with a form of popular music. While it is part of the writer's role to sound out such unlikely correspondences between time periods and musics, there is also a tension inherent in the fact that it is a female composer who is being reclaimed by a critical milieu comprised mostly of men; and that these interpretations of her music began to appear soon after her death (beginning, as we have seen, in her obituary).

Despite her early success at the BBC Radiophonic Workshop, Derbyshire struggled personally and professionally to find a sympathetic context for her work during her lifetime, at one point giving up music altogether for some years. Her occasional collaborations with artist film-makers including Elsa Stansfield, Madelon Hooykaas and Elizabeth Koziman offer, as I have proposed when writing about Circle of Light (Morgan 2016: 68), a glimpse of productive relationships with experimental visual artists which, sadly, were not developed beyond a few works. These self-imposed gaps and absences in Derbyshire's career, combined with the restrictions on creative control and experimental practices imposed by the BBC, are, and should be, frustrating and troubling for researchers into Derbyshire's life and work, for they portray an artist unable for various structural and personal reasons to realise her full potential. However, I believe that these absences and lacunae have made possible her cooption by the musical-critical movement known as hauntology, in which absences, ghosts, temporal anomalies and incomplete memories, combined with ideas of state-controlled 
artistic institutions and the aforementioned popular modernism, are fundamental. It could be said that, within hauntology, women appear as avatars of a utopian post-war Britain, ghostly manipulators of old technology, and reassuring but disembodied voices. In the following section I examine this claim by situating Delia Derbyshire's music and persona in the context of hauntology's preoccupation with the past and its sonic traces, as a gesture towards future research into the gendered as well as temporal relations at work within a phenomenon that has so far lacked a feminist critique.

\section{Listen with Mother: Hauntology and Gender}

The $\mathrm{BBC}$, as is the case with other public service broadcasters, has often been described as paternalistic, with reference to its founder John Reith's ideas of broadcasting as a "social tool" (Hendy 2013) for bringing a "high" standard of cultural and political discourse to a wide listenership, delivered in an authoritative yet kindly manner. Yet in other descriptions it is feminised: a common nickname for the BBC was, for many years, "Auntie Beeb" or just "Auntie". The origins of the nickname are debated, but its effect was to cast the corporation as a sensible, older woman with a familial relationship to the listener or viewer. It was also derogatory in some usages, implying prudishness and closed-mindedness ("Auntie knows best!"); but ultimately, especially viewed in retrospect, Auntie is a benevolent figure who has our best interests at heart. The term "soft coercion", coined by Nina Power to describe the recorded, coded white, middle-class female voices that we hear every day on railway station announcements and automated supermarket checkouts in the UK, points to the ideology behind this kindly yet authoritative female archetype (Power 2014: 23).

Simon Reynolds suggests that some of the music associated with hauntology expresses affection for the days of the "nanny state" (Reynolds 2011:348) of post-war Britain, to use another gendered expression,. He writes, in regard to electronica label Ghost Box:

This lost era of planning and edification represented a paternalism (or perhaps maternalism, given its association with things like free school milk for kids and BBC children's fare like Watch With Mother) that rock'n'roll in some sense rebelled against. ... But by the early 2000s, these bygone ideals of progress started to acquire the romance, pathos and honour of a lost future (Reynolds 2011:348).

If maternalism is one of the absences that hauntology mourns, perhaps it is not surprising that, with a few notable exceptions such as the late Trish Keenan of the band Broadcast, women have been absent from the musical and critical manifestations of it, except as archetypes: maternal or aunt-like voices, witches (a key hauntological theme for artists such as The Advisory Circle is popular representations of the occult), and studio-cloistered public servants such as Derbyshire and Daphne Oram. Hauntology's centring of the male experience is in keeping with the focus on artists' and writers' memories of their own boyhoods, which are invariably referred to in interviews and articles, not only in blogging, where it might be expected, but in academic articles such as Pattie (2016). 
While Mark Fisher's writing on hauntology has engaged with its theoretical and political dimensions, Simon Reynolds's account of the phenomenon, which he and Fisher knowingly titled in homage to Jacques Derrida's concept of the same name, is the one that has been the most legible to musicians and critics, via his Wire article "Society of the Spectral" (Reynolds 2006). However, what began as an observation and framing of certain concerns in electronic music has now become a genre of electronica whose relationship to dance music culture, and to its attendant politics of race and class, is increasingly distant. Pattie (2016), in a useful retrospective account, remarks that hauntology has become depoliticised and that the term is used now to denote certain material and technical qualities:

coming to describe a type of recording that was haunted, or that existed in an indeterminate relation to the past; it bore the spectral imprint of previous styles and technologies, mixed with techniques and approaches available only to the contemporary musician (Pattie 2016: 195).

The articles by Carmody and Hollings from the early 2000s signal an early expression of a hauntological framing of Derbyshire's music. Since then, Derbyshire has been called upon to represent a number of traits associated with hauntology, such as the celebration of an educational "maternalist" culture as epitomised by the BBC, and the techniques and devices of analogue music production. She epitomises popular modernism through her role in creating widely disseminated experimental electronic music, as well as lending support to the idea that such music prefigured or is connected to EDM and electronica.

As I state in the opening section, Derbyshire's life and work have also become symbolic of a wider history of women's electronic music-making, both classical or popular, by musicians, scholars and journalists. My concluding section examines this narrative and Derbyshire's place within it. With reference to feminist archival practice and dance music journalism, I consider the ways in which claiming Derbyshire as a pioneering figure in an area such as EDM can be problematic as well as celebratory.

\section{Herstories of Electronic Music: Delia Derbyshire and the Feminist ARCHIVE}

As writers including Rodgers (2015), Goh (2014), Bliss (2013) and Morgan (2017) have pointed out, media accounts of women in electronic music history often describe them as "pioneers": exceptional figures whose achievements are portrayed through a lens of both sacrifice and empowerment. Following Rodgers' (2015) critique of this phenomenon, and drawing on Sally MacArthur's (2010) writing about the positivist, empirical frameworks often used in liberal feminist musicology, ${ }^{12}$ I perceive a decontextualising effect in the numerous Buzzfeed-style lists that appear in online media, which bring together women such as Pauline Oliveros, Bebe Barron, Laurie Spiegel and Daphne Oram-and of course, Delia Derbyshire - to illustrate the idea of a tradition or lineage of women experimenting with electronic music. I propose that this can contribute to the commodification of such composers' work, to the extent where, in the currently crowded market for repackaged 
archive recordings of electronic music, gender becomes akin to one of the "microgenres" more commonly associated with EDM (Morgan 2017: 243).

There is a risk that the critiques mentioned above can have a counterproductive effect on efforts to reinstate the historical achievements of women, and amplify and celebrate their contributions to the field of electronic music-contributions which have frequently gone unnoticed. As Farrugia (2012) notes, women producers and DJs have often been ignored in the few histories that have been written of EDM (Farrugia 2012: 27). Additionally, as Farrugia (2012), Rodgers (2015) and media theorists such as Wendy Chun have pointed out, women's participation in all kinds of technological-cultural activities, from recordbuying to computing, has frequently been omitted from the histories of those practices. Writers and musicians such as Antye Greie-Ripatti draw on the history of women's electronic music-making to strengthen networks of women making electronica and EDM in the present day. ${ }^{13}$ In this way, historical narratives of women in electronic music can become resources for activists, demonstrating "a desire to take control of the present though a reorientation of the past" (Eichhorn 2013:7).

Eichhorn refers here to a particular set of feminist archives-materials from feminist activist communities, such as pamphlets, zines and so on. However, her account of the archival turn in feminist scholarship is useful in considering how archival recordings and images of musicians such as Delia Derbyshire can be read as items of feminist historymaking or utilised for feminist aims, even if Derbyshire herself did not identify as a feminist (Hutton 2000). ${ }^{14}$ In accounts such as those by Blanning and The Black Madonna (2015) and the uncredited DJ magazine article "These Are Dance Music's Most Influential Female Pioneers" (2017), a connection is drawn between Derbyshire and EDM DJs and producers of the present day in order to strategically demonstrate that innovation by exceptional women in electronic music production has historical precedents.

Yet as well-intentioned as many iterations of it might be, it can be argued that the "female pioneers" narrative invites a recapitulation to heteropatriarchal narratives which welcome women only as anomalies within established systems (Morgan 2017: 241). As Butler (2006: 46) notes, such an approach perpetuates rather than counters gender norms:

Existing accounts tend to emphasise the creativity of a few individuals, and they often include elements of heroic struggle as well: obstacles to be overcome and technology to be conquered. ... It is not just that the heroes (the specific individuals) of these stories are male, but that the stories themselves are masculine kinds of stories.

In the case of Delia Derbyshire's story, one might see a masculine aspect to the way in which she is characterized as a "hero" or genius who achieved great technical mastery. In this way, she becomes the masculine subject of the story, thus elevating her to a point at which she can be considered on an equal footing with her male contemporaries, and part of what Tara Rodgers calls a "patrilineal history" of electronic music (Rodgers 2010: 15). One could also say that equally "masculine" is the characterization of Derbyshire as a vulnerable figure lost to history, not least in the insistence that she has needed rescuing or rehabilitating from 
historical neglect, an account that denies her agency and casts her as dependent on the heroic efforts of her rescuers, such as Wikidelia's Martin Guy.

Butler's proposal also helps us to avoid focusing too heavily on the gender of the writers of such histories. While it is true that, so far, most feminist scholarship of electronic music history has been undertaken by female-identified writers, it is also the case that both men and women writing in the media perpetuate the "masculine stories" that Butler identifies. Such stories gloss over the difficulties and inequalities experienced by the women of the past in favour of an empowering narrative, as well as deflecting attention from the inequalities that are still rife in electronic music of all kinds-and which are indeed perpetuated by some of the same people who celebrate women's historical achievements. For example, $D J$, despite its assertion that "arguably the most innovative artists of all in electronic sound are women" (DJ Mag 2017), was widely criticised in 2016 when the cover of its 25th anniversary issue featured 25 male DJs and none of any other gender.

Historians of EDM must be especially alert to the perpetuation of reductive narratives of electronic music, even if they appear to redress gender inequalities. For example, many of articles about "female pioneers" that I cite in "Pioneer Spirits" (Morgan 2017) focus on composers such as Delia Derbyshire, Suzanne Ciani and Eliane Radigue, rooting "electronic music" within a white, Euro- and US-centric context of studio-based composition using highly advanced technology, often within academic or national broadcasting institutions. It is my concern that the history of EDM, which has developed outside of those institutions, and in which the interstices of class, race, geography and sexuality as well as gender are of such importance to the development of its subgenres and scenes, is misrepresented when set in this dominant, "patrilineal" model of electronic music history, which for the most part has accommodated women only if they are white, Western European or North American, and educated within certain academic frameworks.

While it follows the list-based format of many other articles about "female pioneers", Lisa Blanning and The Black Madonna’s (2015) article for Mixmag, "20 Women Who Shaped the History of Dance Music", challenges this model in some important ways. Their account begins with Delia Derbyshire but does not continue with a list of similar composers, instead highlighting the contributions of promoters, shop owners and A\&R staff as well as musicians and DJs. The list is inclusive of queer and trans women, and women of colour, and mentions collaborative practices, such as the Chicago House DJ collective Superjane. Here, with the localised practitioner's perspective of The Black Madonna, who is a Chicago-based DJ, Delia Derbyshire is positioned not only as a solitary genius but also an actor within a diverse conversation across race, time, geography and practice, with the purpose of making a "political intervention into the present" (Eichhorn 2013: 8).

To conclude, it is essential that writers, musicians and artists are able respond to the official and unofficial archives of electronic music in creative and challenging ways, creating new works, new stories and, should they wish, new origin myths, genealogies and conceptual leaps and bounds: the purpose of this essay is not to proscribe any such efforts, nor to set in place my own idea of who Delia Derbyshire was and is. She can be recognised as a figure 
of empowerment for women musicians, a representative of a period of modernist popular culture, a technological innovator, and a progenitor for British EDM: her work and what we know of her life allow for all these interpretations. However, if feminist historians of electronic music are, as Antoinette Burton writes, to aim to "denaturalise the presumptive boundaries of the official archive space" (Burton 2006: 8), we should likewise critique the unofficial archive spaces that have constructed similar boundaries of their own, asking that the reorientation towards history represented by these various reclamations of the work of Delia Derbyshire are met with resistance to forming new dominant narratives around gender, culture and electronic music, and with efforts to effect change in the present.

\section{ACKNOWLEDGEMENTS}

I would like to thank Magdalena Olszanowski and Rebekah Farrugia for their invaluable editorial support during the writing of this paper. Thanks must also go to the BBC Written Archives, David Butler of the Delia Derbyshire Archive, and the authors of WikiDelia.net for providing access to archive materials.

\section{NOTES}

1 Louis Niebur unpacks the complex relationship between "special sound" and incidental music in his account of the BBC Radiophonic Workshop, noting that in some cases "special sound" functions as music as well as sound effect (Niebur 2010: 75-7).

2 < https://deliaderbyshireday.wordpress.com/>

3 Kember's interview carried out for Surface zine can be accessed here: $<$ http://www.deliaderbyshire.org/interview surface.php> (accessed 26 October 2017), and Cavanagh's for Boa zine can be accessed here: <http://www.delia-derbyshire.org/interview boa.php $>$ (accessed 26 October 2017).

4 <http://lists.topica.com/lists/delia> (accessed April 2017). A related Facebook group "The Electronic Church of St. Delia" is currently active: <http://www.facebook.com/TheElectronic-Church-of-St-Delia-169766083079916> (accessed April 2017).

5 <http://www.centreforscreenstudies.manchester.ac.uk/delia.htm> (accessed September 2017).

6 As more academic accounts of Derbyshire have been produced since the increase in media accounts of her life and work, Hills's writing on the "scholar-fan" (the academic who also maintains a fan identity) and the "fan-scholar" (the fan who uses academic theory in their writing) might also be useful in drawing attention to the ways in which "fan and academic identities can be hybridised or brought together" (Hills 2002: xxx).

7 In 2012, the UK-based label Public Information released archive recordings from the 1960s by British inventor/composer F. C. Judd and new releases by EDM/electronica artists Ekoplekz and Austin Caesar. An early example of this tendency can be seen in Rephlex Records' corelease, in 2003, of the LP compilation Music From The BBC Radiophonic Workshop. 
8 Such as Recollection GRM, an imprint of Editions Mego, that releases archival works from the GRM studio, Paris.

9 On a YouTube post of "Dance from Noah", I notice that a number of commenters, rather than citing Warp records, now write that it sounds like grime, referring perhaps to the bright, minor-key synthesizer lines heard in grime instrumentals.

10 The piece was made using elements from cues that Derbyshire had made for specific programmes, for example a 1965 radio programme on science and technology in Finland (Percival 2013).

11 Carmody writes elsewhere, "Pot Au Feu" is: "three minutes and nineteen seconds of paranoia, virtually a rave track circa 1991 in its structure; a stuttering, pounding teleprinter-paced bassline worthy of Timbaland as the tension builds, then a moment of chaos and crisis, an alarm-bell of a hook recalling the 'panic/excitement' lines so prevalent in early '90s hardcore" (Carmody 2000).

12 MacArthur refers to studies in which data is used to show, for example, the low number of female composers programmed in concert halls, in the hope that those institutions will then address this lack.

13 Greie-Ripatti's “Nerdgirls” mix (<http://nerdgirls.poemproducer.com/>) demonstrates this approach.

14 In Hutton's interview, Derbyshire is quoted as saying, "A producer once said to me, 'You must be an ardent feminist,.... I said 'What!', I hadn't even thought in those words".

\section{REFERENCES}

Blanning, Lisa and The Black Madonna. 2015. "20 Women Who Shaped The History of Dance Music". Mixmag. < http://mixmag.net/feature/20-women-who-shaped-the-history-of-dancemusic/16> (accessed 26 October 2017).

Bliss, Abi. 2013. "Invisible Women". The Wire. <http://www.thewire.co.uk/in-writing/columns/ abi-bliss invisible-women $>$ (accessed 26 October 2017).

Briscoe, Desmond and Curtis-Bramwell, Roy. 1983. First Twenty-five Years: BBC Radiophonic Workshop. London: BBC.

Burton, Antoinette. 2006. Archive Stories: Facts, Fictions, and the Writing of History. Durham, NC: Duke University Press.

Butler, David. 2014. “'Way out-of This World!' Delia Derbyshire, Doctor Who and the British Public's Awareness of Electronic Music in the 1960s". Critical Studies in Television 9(1): 62-76. London: Sage. <https://doi.org/10.7227/cst.9.1.5>.

Butler, Mark J. 2006. Rhythm, Meter, and Musical Design in Electronic Dance Music. Bloomington: Indiana University Press.

Carmody, Robin. 2000. Title of blog post unknown. Elidor. Quoted on delia-derbyshire.net. $<$ http://delia-derbyshire.net/\#PotAuFeu > (accessed 28 October 2017).

Carmody, Robin. 2001. "Delia Derbyshire RIP”. The Wire 210, August: 14. 
Create Digital Media 2008a. "Delia Derbyshire Recordings Found, Including Ahead-of-its-Time Dance Track”. 18 July. < http://cdm.link/2008/07/delia-derbyshire-recordings-foundincluding-ahead-of-its-time-dance-track/> (accessed 26 October 2017).

Create Digital Media 2008b. "Archivist Responds: Yes, Virginia, Delia Derbyshire Really Was That Awesome". 29 July. < http://cdm.link/2008/07/archivist-responds-yes-virginia-deliaderbyshire-really-was-that-awesome/> (accessed 26 October 2017).

DJ Mag. 2017. “These Are Dance Music's Most Influential Female Pioneers”. 8 March. $<$ https://djmag.com/features/female-electronic-music-pioneers $>$ (accessed 26 October 2017).

Eichhorn, Kate. 2013. The Archival Turn in Feminism: Outrage in Order. Philadelphia: Temple Press. Farrugia, Rebekah. 2012. Beyond the Dance Floor: Female DJs, Technology and Electronic Dance Music Culture. Bristol: Intellect.

Fisher, Mark. 2014. Ghosts of My Life: Writings on Depression, Hauntology and Lost Futures. London: Zero.

Goh, Annie. 2014. "Confrontation, Diplomacy, Subversion-Strategies for Feminist Activism in Sound?" University of the Arts, London. "Sound:Gender:Feminism:Activism" Conference. Abstract: <http://hernoise.org/wp-content/uploads/2015/10/SGFA-2014Booklet.pdf> (accessed 26 October 2017).

Grant, Catherine. 2011. "Fans of Feminism: Re-writing Histories of Second-wave Feminism in Contemporary Art”. Oxford Art Journal 34(2): 265-86. Oxford: Oxford University Press. <https://doi.org/10.1093/oxartj/kcr021 >.

Hendy, David. 2013. Public Service Broadcasting. London: Palgrave.

Hills, Matt. 2002. Fan Culture. London and New York: Routledge.

Hollings, Ken. 2002. "Review: The BBC Radiophonic Workshop BBC Radiophonic Music". The Wire, 225, November: 66.

Hutton, Jo. 2000. "Radiophonic Ladies”. Sonic Arts Network magazine. Archived at < http://delia-derbyshire.net/sites/ARTICLE2000JoHutton.html> (accessed 26 October 2017).

MacArthur, Sally. 2010. Towards a 21st Century Feminist Politics of Music. Farnham: Ashgate.

Morgan, Frances. 2017. "Pioneer Spirits: New Media Representations of Women In Electronic Music History". Organised Sound 22(2): 238-49. Cambridge: Cambridge University Press. $<$ https://doi.org/10.1017/s1355771817000140>.

Morgan, Frances. 2016. "Delia Derbyshire \& Elsa Stansfield: Circle of Light". Review in The Wire, 391, September: 68.

Niebur, Louis. 2010. Special Sound: The Creation and Legacy of the BBC Radiophonic Workshop. Oxford: Oxford University Press.

Pattie, David. 2016. "Stone Tapes: Ghost Box, Nostalgia and Postwar Britain”. In The Oxford Handbook of Music and Virtuality, ed. Shara Rambarran and Sheila Whiteley, 392-408. Oxford: Oxford University Press.

Percival, James. 2013. “Delia Derbyshire's Creative Process”. MA thesis (Musicology), University of Manchester.

Power, Nina. 2014. "Soft Coercion, the City, and the Recorded Female Voice". In The Acoustic City, ed. Matthew Gandy and BJ Nilson. Berlin: Jovis.

Reynolds, Simon. 2006, "Society of the Spectral". The Wire, 273, November: 26-33. 
Reynolds, Simon. 2011. Retromania: Pop Culture's Addiction to its Own Past. London: Faber \& Faber.

Rodgers, Tara. 2015. "Tinkering with Cultural Memory: Gender and the Politics of Synthesizer Historiography”. Feminist Media Studies 1(4): 5-30.<https://doi.org/10.1525/fmh.2015.1.4.5>.

Rodgers, Tara. 2010. Pink Noises: Women on Electronic Music and Sound. Durham, NC: Duke University Press.

Rogerson, Ben. 2008. "New Evidence that Doctor Who Composer Invented Dance Music". 18 July. <http://www.musicradar.com/news/tech/new-evidence-that-doctor-who-composerinvented-dance-music-165571 $>$ (accessed 26 October 2017).

Wajcman, Judy. 1991. Feminism Confronts Technology. Pennsylvania: Penn State University Press.

Winter, Teresa. 2015. "Delia Derbyshire: Sound and Music For The BBC Radiophonic Workshop, 1962-1973”. PhD thesis (Music) University of York.

Wrench, Nigel. 2008. "Lost Tapes of the Dr Who Composer". BBC News, 18 July. <http://news.bbc.co.uk/1/hi/entertainment/7512072.stm $>$ (accessed 26 October 2017).

\section{DISCOGRAPHY}

BBC Radiophonic Music. 2002. BBC Radio Enterprises (CD COMP): REC25MCD. <https://www.discogs.com/BBC-Radiophonic-Workshop-BBC-Radiophonic-Music/ release/173394>.

Derbyshire, Delia. 1968. BBC Radiophonic Music, BBC Radiophonic Workshop. BBC Radio Enterprises (LP COMP): REC 25M.

<https://www.discogs.com/BBC-Radiophonic-Workshop-BBC-Radiophonic-Music/master/84825>.

Derbyshire, Delia. 1972. "Dance from Noah”. Sounds from...EMS, Electronic Music Studios (London) Limited (Flexidisc COMP): promotional release, no serial number. <https://www.discogs.com/Various-Sounds-From-EMS-Synthi/release/670765>.

Derbyshire, Delia and Stansfield, Elsa. 2016 (recorded 1972). Circle of Light (Original Electronic Soundtrack). Trunk LP: JBH061LP. $<$ https://www.discogs.com/Delia-Derbyshire-And-Elsa-Stansfield-Circle-Of-Light-OriginalElectronic-Soundtrack/release/8823727>.

Music From The BBC Radiophonic Workshop (2003). BBC Music/Rephlex (LP COMP): CAT147LP. <https://www.discogs.com/BBC-Radiophonic-Workshop-Music-From-The-BBCRadiophonic-Workshop/release/212869>.

FILMOGRAPHY

Blake, Kara. 2009. The Delian Mode. Canada: Philtre Films. < http://www.imdb.com/title/tt1442559/>. <https://www.youtube.com/watch?v=nXnmSgaeGAI $>$ (accessed 26 October 2017). 